\title{
Decomposition analysis of the impact of economic growth on ammonia and nitrogen oxides emissions in the European Union
}

\author{
Maria Hnatyshyn \\ Faculty of Economics, \\ Ivan Franko National University of Lviv \\ Ukraine \\ maria.hnatyshyn@Inu.edu.ua
}

\begin{abstract}
This study investigates the environmental consequences of economic growth. Global environmental problems tend to aggravate along with global economic development. A number of harmful chemical compounds are being emitted into the air every day. An econometric model describing the influence of GDP per capita growth, foreign trade intensity and the volume of primary energy consumption on NOx and NH3 emissions is estimated in the paper. The data on the $28 \mathrm{EU}$ countries is analyzed. The main findings support the EKC hypothesis. The relationship between per capita income and emissions of both NOx and NH3 falls into the EKC pattern. The estimation results on international trade intensity influencing the emissions are insignificant. The growth of primary energy consumption increases the emissions of both gases. This effect is greater for NOx since power plants are among the most significant sources of its emission. Given that the primary energy consumption in the EU continues to grow, there is a risk of further emissions growth in the energy sector, which should be taken into account by policymakers.
\end{abstract}

Keywords: Environmental Kuznets Curve, GDP, pollution haven hypothesis, primary energy consumption, the European Union.

JEL Classification: O10, O13, F18, Q40

\section{INTRODUCTION}

In line with the ongoing economic growth, the global environmental problems become more severe. But at the same time, humanity gets more resources and experience in tackling the related problems. In most of the "developed" world, we can see growing concerns about the state of the environment. A good example in this regard is the Paris Agreement, a universal, legally binding global climate deal. The problem of climate change it addresses is one of the most important and global problems. However, not only greenhouse gases are emitted into the atmosphere but also a number of other compounds, also harmful to the environment and human health. 
The most popular hypothesis linking economic growth with the environment is the environmental Kuznets curve (EKC) hypothesis (Yandle, et al. 2002). According to this hypothesis, economic growth initially leads to increased emissions but after reaching a certain level of per capita income (the turning point) it causes emissions' decline. The key issue of this study is to confirm or refute this hypothesis. If the EKC hypothesis is confirmed it will be also possible to identify the turning points for chosen pollutants. Besides economic growth, we take into account other possible factors influencing the level of emissions. These are international trade intensity and the volume of primary energy consumption.

To conduct our research we need to choose the type of pollution, which is closely linked to economic activity, causing considerable damage to the environment, and also for which fullest data is available. In this paper, $\mathrm{NO}_{\mathbf{x}}$ and $\mathrm{NH}_{3}$ emissions become the object of the study.

Nitrogen (IV) oxide $\left(\mathrm{NO}_{2}\right)$ is the most frequently mentioned gas in the studies on the group of highly chemically active gases - nitrogen oxides $\left(\mathrm{NO}_{\mathrm{x}}\right)$. $\mathrm{NO}_{2}$ is rapidly generated from car emissions, power plants and also off-road equipment. This gas contributes to the formation of near ground level ozone and small particles pollution. $\mathrm{NO}_{2}$ has a number of adverse effects on the respiratory system (EPA, 2015). Secondary pollutants of nitrogen oxides are nitrous and nitric acid.

Gaseous ammonia $\left(\mathrm{NH}_{3}\right)$ is the most common alkaline gas in the atmosphere. In addition, it is the core component of reactive nitrogen. The largest contributor of $\mathrm{NH}_{3}$ emissions is agriculture, in particular, cattle breeding, other livestock breeding and also $\mathrm{NH}_{3}$-based fertilizers. Other sources are industrial processes, volatilization from the soil and oceans, transport emissions. $\mathrm{NH}_{3}$ plays an important role in the formation of atmospheric dust, deterioration of visibility, transfer of nitrogen through the atmosphere to the most sensitive ecosystems. $\mathrm{NH}_{3}$ emissions also cause climate change (Behera, 2013).

An important question in this regard is whether the efforts of developed countries are successful enough in achieving $\mathrm{NO}_{\mathbf{x}}$ and $\mathrm{NH}_{3}$ emissions' mitigation. To partially answer this question we decompose the GDP growth into few different effects it causes. From this research, we will make conclusions concerning the relationships between incomes of the EU countries and their harmful emissions, and, indirectly, concerning the effectiveness of the related EU environmental policies.

\section{LITERATURE REVIEW}

The first investigation identifying the EKC was conducted by Grossman G. and Krueger A. (Grossman, \& Krueger 1993). They estimated the general influence of economic growth on the environment, caused by the adoption of NAFTA. The results of the investigation showed that along with the increase of real income of the population the air quality at first deteriorates but after reaching $\$ 5000$ per capita income per year it starts improving. After that first investigation, a lot of scientists studied the EKC for different types of pollution for different countries and country groups using different methodologies. In view of a large number of scientific papers on the topic, we will name only those analyzing already conducted EKC studies. Such comprehensive studies were conducted by Yandle B., Vijayaraghavan M., Bhattarai M. (2002); Dasgupta S., Laplante B., Wang H., Wheeler D. (2002); Stern D. (2004); Dinda S. (2004); Van Alstine J., Neumayer E. (2010) and others. Despite a large number of studies, empirical results concerning the EKC for harmful emissions are ambiguous.

Besides EKC hypothesis we employ the pollution haven hypothesis $(\mathrm{PHH})$. According to the $\mathrm{PHH}$ polluting industries tend to relocate from countries with stringent environmental regulations to countries with lax regulations. A number of scientists found out that such a link exists at least partly due to trade effect. For example, Cole M. and Neumayer E. (Cole, \& Neumayer 2005) believe that developed countries reached such a decline in air pollution at a local level at least partly due to importing polluting products from less developed countries. Cole (Cole 2004) analyzes PHH in the context of the EKC and states that the first 
hypothesis is a possible explanation of the second one. In his EKC model, Cole takes into account per capita income, the share of manufacturing in GNP, the share of dirty exports to non-OECD countries in total exports, the share of dirty imports from non-OECD countries in total imports and trade intensity. Having estimated the model for the years 1980-1997 he finds evidence of an inverse relationship of air pollution emissions (including $\mathrm{NO}_{\mathrm{x}}$ ) with the share of pollution-intensive imports from developing countries - pollution haven effect. He also finds a generally positive relationship between trade openness and environmental quality. In most of the cases, trade openness has resulted in a reduction of emissions in OECD countries. So Cole comes to a conclusion that trade openness facilitates environmental improvement.

In our previous work (Hnatyshyn, 2016) we studied the EKC and $\mathrm{PH}$ problem for $\mathrm{CO}_{2}$ and Sulphur oxides. The results of the study confirmed the EKC relationships between economic growth in the EU countries (per capita GDP) and $\mathrm{CO}_{2}$ and $\mathrm{SO}_{x}$ emissions. PHH was tested through trade intensity influence on emissions analysis. We found out that foreign trade intensification decreases $\mathrm{CO}_{2}$ and $\mathrm{SO}_{\mathrm{x}}$ emissions.

Another possible determinant influencing harmful air emissions is the primary energy consumption. For example, Farhani S. and Ben Rejeb J. (Farhani, \& Ben Rejeb, 2012) as well as Shahbaz M., Lean H., Shahbaz Shabbir M. (Shahbaz, et al 2010) take it into account in their investigations. Farhani S. and Ben Rejeb J. conducted a panel study of the relationship between energy consumption, GDP and $\mathrm{CO}_{2}$ emissions for 15 MENA countries for the period from 1973 to 2008. They found out that an increase in energy consumption may lead to the income growth and increase in the $\mathrm{CO}_{2}$ emission. Shahbaz M., Lean $\mathrm{H}$. and Shahbaz Shabbir M. conducted a country study for Pakistan over the period of 1971-2009. Independent variables they used were: energy consumption, economic growth, and trade openness. The results indicated that energy consumption increases $\mathrm{CO}_{2}$ emissions in the short and long run. We think energy consumption determinant is also relevant when studying $\mathrm{NH}_{3}$ and especially $\mathrm{NO}_{\mathbf{x}}$ emissions.

\section{METHODOLOGY}

We conducted an empirical analysis of economic growth influence on $\mathrm{NO}_{\mathrm{x}}$ and $\mathrm{NH}_{3}$ emissions in the EU countries based on a standard EKC regression model according to Stern (2004). We also took into account other potential variables which influence the emissions intensity. They are foreign trade intensity and primary energy consumption. Foreign trade intensity variable helps us to determine the polluting production migration away from the EU countries. A separate evaluation of the influence of the level of primary energy consumption on emissions is a decomposition of GDP growth effects. We have to bear in mind that separate evaluation of this factor can speed the EKC. We use a logarithmic modification of the model to evaluate nonlinear relationships between variables and to impose restrictions on negative values (Hnatyshyn, 2016). So far our model is as follows:

$$
\begin{gathered}
\mathrm{Ln}(\mathrm{E} / \mathrm{POP})_{\mathrm{k}, \mathrm{t}}=\alpha_{0}+\alpha_{1} \ln (\mathrm{GDP} / \mathrm{POP})_{\mathrm{k}, \mathrm{t}}+\alpha_{2}(\ln (\mathrm{GDP} / \mathrm{POP}))_{\mathrm{k}, \mathrm{t}}+\alpha_{3} \ln (\mathrm{T})_{\mathrm{k}, \mathrm{t}}+ \\
+\alpha_{4} \ln (\mathrm{EC} / \mathrm{POP})_{k, \mathrm{t}}+\varepsilon_{\mathrm{k}, \mathrm{t}}
\end{gathered}
$$

where:

E- emissions,

POP - population,

$\mathrm{T}-$ international trade intensity,

$\mathrm{T}=(\mathrm{EXP}+\mathrm{IMP}) / \mathrm{GDP}$

where:

EXP - export, 
IMP - import,

EC - primary energy consumption,

$\alpha_{0}-$ specific parameters for countries and years,

$\varepsilon_{\mathrm{k}, \mathrm{t}}-$ random components vector.

For us, the turning point income (TP) is of specific interest. This is the income level when emissions reach their maximum and start to decline. It can be determined on the basis of the model using the formula:

$$
T P=\exp \left(-\frac{\alpha_{1}}{2 \times\left(\alpha_{2}\right)}\right)
$$

If an EKC assumption is true, the sign of $\alpha_{1}$ will be positive and the $\alpha_{2}$ sign will be negative. This will mean that we have an inverted parabola shaped relationship. The expected sign of $\alpha_{3}$ (trade intensity) for the EU countries, as far as they are developed countries, is negative. Polluting production in most of the developed countries is limited by environmental law and consequently, products produced by polluting industries have to be imported from countries where restrictions are absent or not so strict. The $\alpha_{4}$ sign (primary energy consumption) should be positive as we suspect that increased energy consumption is connected with higher emissions. We suspect that the share of clean energy sources is not growing fast enough.

\section{EMPIRICAL RESULTS AND DISCUSSION}

We carried out an empirical research for 28 countries of the EU. In the investigation we analyzed the influence of economic growth, international trade intensity and primary energy consumption on $\mathrm{NO}_{\mathrm{x}}$ and $\mathrm{NH}_{3}$ emissions for years 1990-2014.

European Environmental Agency (EEA) analyzed the expenditures on air pollution by European industrial companies (EEA 2014). According to their estimations, the overall losses caused by main air pollutants $\left(\mathrm{NH}_{3}, \mathrm{NO}_{\mathrm{x}}, \mathrm{PM}_{10}, \mathrm{SO}_{2}, \mathrm{NMVOCs}\right)$ in the EU constituted 40-115 million euro (2005 prices) in 2012.

Data on $\mathrm{NO}_{\mathrm{x}}$ and $\mathrm{NH}_{3}$ emissions we gathered from WebDab database of the Cooperative Programme for Monitoring and Evaluation of the Long-Range Transmission of Air Pollutants in Europe (EMEP) (EMEP 2016). Total emission of these gases by the EU countries are presented in Figure 1.

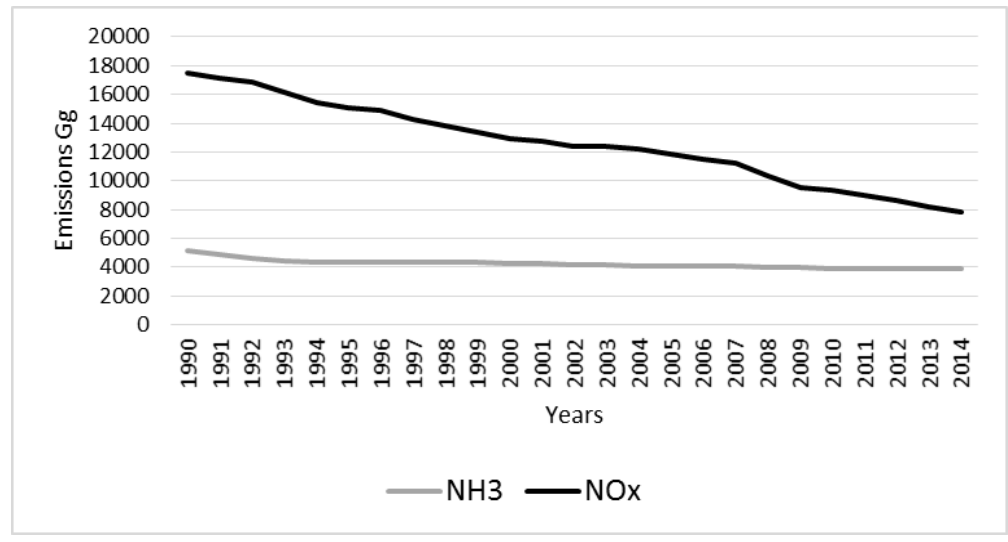

Figure 1. Dynamics of $\mathrm{NO}_{\mathrm{x}}$ and $\mathrm{NH}_{3}$ emissions in the EU. Source: EMEP (2016) 
As we mentioned in the introduction part of the paper, $\mathrm{NO}_{x}$ and $\mathrm{NH}_{3}$ are less global polluters than $\mathrm{CO}_{2}$. The empirical results of our investigation for those gases have to be more similar to the results for $\mathrm{SO}_{\mathrm{x}}$ (see Hnatyshyn, 2016). $\mathrm{NO}_{\mathrm{x}}$ and $\mathrm{NH}_{3}$ have a local influence and not very distant in time consequences for people's health. According to the theory, it should accelerate the decrease of emission of these gases with the increase of per capita income.

Data on GDP and the share of imports and exports in GDP was obtained from the World Development Indicators database (WDI) of the World Bank WB (2016). Data on primary energy consumption was obtained from the US Energy Information Agency (EIA) (2016). If to analyze the average primary energy consumption in the $28 \mathrm{EU}$ countries (Figure 2), we can see the increasing trend, i.e. energy consumption in the EU increases.

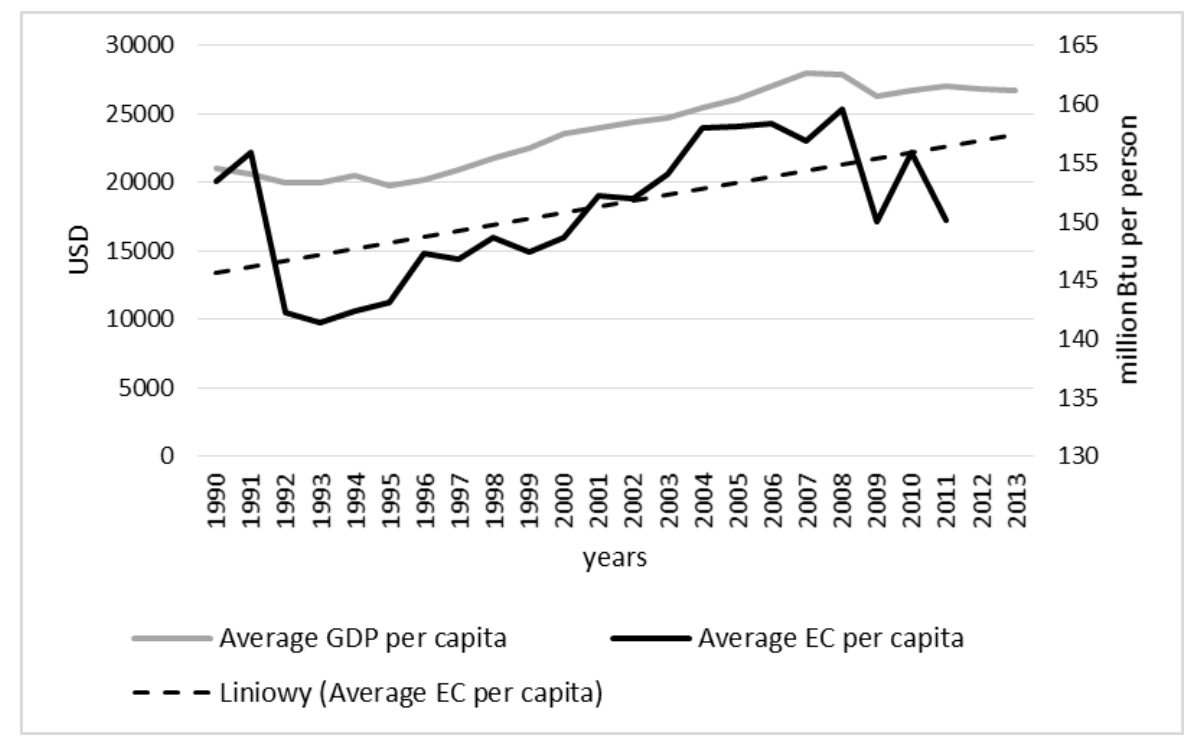

Figure 2. Thy dynamics of per capita primary energy consumption in comparison to per capita GDP

Sources: based on WB (2016) and EIA (2016) data.

We carried out the model estimation using Eviews program. We employed estimated generalized least squares method using cross-section weights. That means that the weights are estimated in primary regression with equal weights and then used in the least squares method in the second stage of estimation.

We used fixed effects as Stern suggests (Stern, 2004). It means that intersection points with the axis are estimated for each country separately. When specific effects for countries correlate with explanatory (independent) variables, random effects model cannot be adequately estimated. Such correlation is common when using panel data for countries.

The redundant fixed effects test and the Hausman Test confirm our speculations. Redundant fixed effects test tests the joint significance of the fixed effects estimates in the least squares specifications. In Table 2 the output of the test for the equation where $\mathrm{NH}_{3}$ is the dependent variable is presented. 
Redundant fixed effects test of the model for $\mathrm{NH}_{3}$

\begin{tabular}{|l|c|c|c|}
\hline \multicolumn{3}{|c|}{ Test cross-section fixed effects } \\
\hline Effects Test & Statistic & d.f. & Prob. \\
\hline Cross-section F & 480.437357 & $(27,527)$ & 0.0000 \\
\hline
\end{tabular}

The null hypothesis that the cross-section fixed effects are redundant is strongly rejected. The same results were obtained for the equation where $\mathrm{NO}_{\mathrm{x}}$ is the dependent variable (Table 2).

Table 2

Redundant fixed effects test of the model for $\mathrm{NO}_{\mathrm{x}}$

\begin{tabular}{|c|c|c|c|}
\hline \multicolumn{4}{|c|}{ Test cross-section fixed effects } \\
\hline Effects Test & Statistic & d.f. & Prob. \\
\hline Cross-section F & 111.934690 & $(27,527)$ & 0.0000 \\
\hline
\end{tabular}

The Hausman test tests the null hypothesis that the random effects are uncorrelated with the explanatory variables and, consequently, the random effects are better than fixed. So we estimated the model using random effects and performed the Hausman Test. According to the test results, we reject the hypothesis that random effects are better than fixed for both $\mathrm{NO}_{\mathrm{x}}$ (Table 3) and $\mathrm{NH}_{3}$ (Table 4).

Table 3

The Hausman Test of the model for $\mathrm{NO}_{\mathrm{x}}$

\begin{tabular}{|c|c|c|c|}
\hline \multicolumn{4}{|c|}{ Correlated Random Effects - Hausman Test } \\
\hline \multicolumn{4}{|c|}{ Test cross-section random effects } \\
\hline Test Summary & Chi-Sq. Statistic & Chi-Sq. d.f. & Prob. \\
\hline Cross-section random & 104.911911 & 4 & 0.0000 \\
\hline
\end{tabular}

Table 4

The Hausman Test of the model for $\mathrm{NH}_{3}$

\begin{tabular}{|c|c|c|c|}
\hline \multicolumn{4}{|c|}{ Correlated Random Effects - Hausman Test } \\
\hline \multicolumn{4}{|c|}{ Test cross-section random effects } \\
\hline Test Summary & Chi-Sq. Statistic & Chi-Sq. d.f. & Prob. \\
\hline Cross-section random & 59.488374 & 4 & 0.0000 \\
\hline
\end{tabular}

To test the models for heteroscedasticity we conducted Breusch-Pagan LM test. Table 5 represents the results of the test for the model in which $\mathrm{NO}_{\mathrm{x}}$ is a dependent variable. According to the test results, the probability of the hypothesis of no cross-section dependence is less than 0.05 . That means error structure is heteroscedastic.

Table 5

Residual Cross-Section Dependence Test of the model for $\mathrm{NO}_{\mathrm{x}}$

\begin{tabular}{|c|c|c|c|}
\hline \multicolumn{3}{|c|}{ Null hypothesis: No cross-section dependence (correlation) } \\
\hline Test & Statistic & d.f. & Prob. \\
\hline Breusch-Pagan LM & 2424.520 & 378 & 0.0000 \\
\hline
\end{tabular}


Table 6 represents the results of the test for the model for $\mathrm{NH}_{3}$. In this case test results also show the presence of heteroscedasticity.

Table 6

Residual Cross-Section Dependence Test of the model for $\mathrm{NH}_{3}$

\begin{tabular}{|c|c|c|c|}
\hline \multicolumn{3}{|c|}{ Residual Cross-Section Dependence Test } \\
\hline Null hypothesis: No cross-section dependence (correlation) & Prob. \\
\hline Test & Statistic & 378 & 0.0000 \\
\hline Breusch-Pagan LM & 1894.223 & d.f. & \\
\hline
\end{tabular}

In the case of heteroskedastic, correlated error structure and autocorrelation structure, which is our case, it would be good to use cross-section SUR for correction, but the number of observations is insufficient for this option. So we used cross section weights in estimating the models. In this case, EViews estimates a feasible GLS specification assuming the presence of cross-section heteroscedasticity to estimate a feasible GLS specification.

The results of the model estimation for $\mathrm{NO}_{\mathrm{x}}$ are presented in Table 7.

Results of the model estimation for $\mathrm{NO}_{\mathrm{x}}$

\begin{tabular}{|c|c|c|c|c|}
\hline \multicolumn{5}{|c|}{ Dependent variable: $\mathrm{Ln}\left(\mathrm{NO}_{\mathrm{x}} / \mathrm{POP}\right)$} \\
\hline Independent variables & Coefficient $\alpha$ & Standard error & t-Statistic & Probability \\
\hline $\mathrm{C}($ constanta $)$ & -34.41212 & 1.481055 & -23.23487 & 0.0000 \\
\hline $\operatorname{Ln}(G D P)$ & 4.992961 & 0.301858 & 16.54078 & 0.0000 \\
\hline$(\operatorname{Ln}(G D P))^{2}$ & -0.300743 & 0.016782 & -17.92029 & 0.0000 \\
\hline $\operatorname{Ln}(\mathrm{EC})$ & 0.841798 & 0.060036 & 14.02160 & 0.0000 \\
\hline $\operatorname{Ln}(T)$ & -0.028196 & 0.033030 & -0.853648 & 0.3937 \\
\hline Method: & \multicolumn{4}{|c|}{ Pooled EGLS (Cross-section weights) } \\
\hline Total observations: & \multicolumn{4}{|c|}{559} \\
\hline Adjusted R-squared & \multicolumn{4}{|c|}{0.886477} \\
\hline Durbin-Watson statistics & \multicolumn{4}{|c|}{0.415282} \\
\hline
\end{tabular}

As we can see from Table 7, econometric analysis confirms the EKC for $\mathrm{NO}_{\mathrm{x}}$. Trade intensity according to the model estimation results is insignificant and we can make no conclusions concerning the influence of $\mathrm{T}$ on $\mathrm{NO}_{\mathrm{x}}$ emissions. The increase in per capita primary energy consumption by 1 million BTU causes 0.841798 increase of $\mathrm{NO}_{\mathrm{x}}$ emissions. The turning point for $\mathrm{NO}_{\mathrm{x}}$ is:

$$
\mathrm{TP}_{\mathrm{NOx}}=\exp \left(-\frac{4.992961}{2 \times(-0.300743)}\right)=4028.070259 \mathrm{USD}
$$

The level of TP is lower than for $\mathrm{CO}_{2}$ (approximately $\$ 8000$ per capita, as we found out in our previous research (Hnatyshyn 2016)) which confirms the theory. The more global the type of pollution is and the more distant in time are the consequences - the higher is the income level needed for pollution to decline. Demand for a clean local environment grows first.

The results of model estimation for $\mathrm{NH}_{3}$ are presented in Table 8 . 
Results of the model estimation for $\mathrm{NH}_{3}$

\begin{tabular}{|c|c|c|c|c|}
\hline \multicolumn{5}{c}{ Dependent variable: $\mathrm{Ln}\left(\mathrm{NH}_{3} / \mathrm{POP}\right)$} \\
\hline \multicolumn{1}{c|}{ Independent variables } & Coefficient $\alpha$ & Standard error & t-Statistic & Probability \\
\hline $\mathrm{C}($ constanta) & -22.35284 & 1.140691 & -19.59587 & 0.0000 \\
\hline $\mathrm{Ln}(\mathrm{GDP})$ & 2.432930 & 0.226408 & 10.74576 & 0.0000 \\
\hline$(\mathrm{Ln}(\mathrm{GDP}))^{2}$ & -0.144492 & 0.011922 & -12.11942 & 0.0000 \\
\hline $\mathrm{Ln}(\mathrm{EC})$ & 0.193174 & 0.037919 & 5.094349 & 0.0000 \\
\hline $\mathrm{Ln}(\mathrm{T})$ & -0.027781 & 0.025873 & -1.073738 & 0.2834 \\
\hline Method: & \multicolumn{3}{c}{ Pooled EGLS (Cross-section weights) } \\
Total observations: & 559 & \\
Adjusted R-squared & 0.964774 & \\
Durbin-Watson statistics & 0.336799 & \\
\hline
\end{tabular}

Based on the model estimation we conclude that there is the EKC relationship between per capita GDP and $\mathrm{NH}_{3}$ as in the case of $\mathrm{NO}_{\mathbf{x}}$ emissions. The variable of international trade intensity is insignificant in our model. The increase in energy consumption increases $\mathrm{NH}_{3}$ emissions. The turning point for $\mathrm{NH}_{3}$ is:

$$
T P_{N H 3}=\exp \left(-\frac{2.432930}{2 \times(-0.144492)}\right)=4531.887496 U S D
$$

At the beginning of our sample, only seven countries had the level of income lower than the level of both turning points estimated by us. The turning point would be higher if we didn't estimate the energy consumption separately. The turning point locates at the higher income level than for $\mathrm{NO}_{\mathrm{x}}$ but much lower than for $\mathrm{CO}_{2}$.

The model estimation results confirm the EKC for both types of pollution. There is a direct relationship between energy consumption and emissions of both harmful gases. That means that the share of clean energy sources in energy consumption doesn't grow sufficiently quickly compared to the growth of energy consumption.

\section{CONCLUSIONS}

Based on the model estimation results we conclude that there is a relationship between economic growth and state of the environment. For both studied types of pollution, it is the EKC relationship. The turning point income for $\mathrm{NO}_{\mathrm{x}}$ and $\mathrm{NH}_{3}$ constitutes approximately four and four and a half thousand USD per capita respectively, which is two times lower than for $\mathrm{CO}_{2}$. These results show that with economic growth the demand for a clean local environment grows first and the demand for a clean global environment grows only later.

Primary energy consumption growth increases the emissions of both polluting gases. This influence is stronger for $\mathrm{NO}_{\mathrm{x}}$ as power plants are an important source of its emission into the atmosphere. As primary energy consumption in the EU countries continues to grow, there is a risk of further growth of pollution in the energy sector. This sector in Europe is still too dependent on fossil fuels and economic growth usually demands more energy consumption.

The examination of the causal relationship between GDP, energy consumption, and emissions growth has important policy implications both for EU and no-EU countries. First of all, it shows that the mechanism of the EKC works for the EU countries. That means that the economic system works 
consistently with the environmental system. This pattern of economic and environmental policy can be copied by developing countries. The second implication is that the energy sector considerably increases emissions in the EU. Clean energy and energy-efficient development should be one of the main environmental concerns of the EU countries.

From the other side, energy consumption may be one of the components fostering economic growth. In its turn, economic growth effect on emissions may offset the negative effect of energy consumption. This is an important question especially for developing countries, to give a comprehensive answer to which further research taking into account a broader scope of indicators and possible relationships between them is required.

\section{REFERENCES}

Behera, S. N., Sharma, M., Aneja, V. P., \& Balasubramanian, R. (2013). Ammonia in the atmosphere: a review on emission sources, atmospheric chemistry and deposition on terrestrial bodies. Environmental Science and Pollution Research, 20(11), 8092-8131. doi:10.1007/s11356-013-2051-9

Cole, M. A. (2004). Trade, the pollution haven hypothesis and the environmental Kuznets curve: examining the linkages. Ecological Economics, 48(1), 71-81. doi:10.1016/j.ecolecon.2003.09.007

Cole, M. A. \& Neumayer, E. (2005). Environmental policy and the environmental Kuznets curve: can developing countries escape the detrimental consequences of economic growth? International Handbook of Environmental Politics, Cheltenham and Northampton: Edward Elgar, p. 298-318. doi:10.4337/9781845425555.00029

Dasgupta, S., Laplante, B., Wang, H., \& Wheeler, D. (2002). Confronting the Environmental Kuznets Curve. Journal of Economic Perspectives, 16(1), 147-168. doi:10.1257/0895330027157

Dinda, S. (2004). Environmental Kuznets Curve Hypothesis: A Survey. Ecological Economics, 49(4), 431-455. doi:10.1016/j.ecolecon.2004.02.011

EEA. (2014). Costs of air pollution from European industrial facilities 2008-2012 - an updated assessment. EEA Technical report No 20, Luxembourg. Retrieved December 14, 2016, from https://www.eea.europa.eu/publications/costs-of-air-pollution-2008-2012

EIA. (2016). International Energy Statistics. Retrieved December 14, 2016, from http:/ / www.eia.gov/cfapps/ipdbproject/IEDIndex3.cfm?tid=44\&pid=44\&aid=2

EMEP. (2016). WebDab database. Retrieved November 25, 2016, from http://www.ceip.at/ms/ceip home1/ceip home/webdab emepdatabase

EPA (2015). Nitrogen Dioxide. Retrieved October 10, 2016, from https://www.epa.gov/no2-pollution

Farhani, S., \& Ben Rejeb, J. (2012). Energy Consumption, Economic Growth and $\mathrm{CO}_{2}$ Emissions: Evidence from Panel Data for MENA Region. International Journal of Energy Economics and Policy, vol. 2, nr 2, p. 71-81.

Grossman, G., \& Krueger, Alan B. 1993. Environmental impact of a North American Free trade Agreement. The USMexico free trade agreement, ed. By P. Garder, Cambridge, p. 13-56. doi:10.3386/w3914

Hnatyshyn, M. (2016). Decomposition of carbon dioxide and Sulphur oxides emissions intensity change in the European Union. Ekonomia. Rynek, gospodarka, spoteczeństwo, 44, 31-50. doi: 10.17451/eko/44/2016/144

Shahbaz, M., Lean, H. H., \& Shahbaz Shabbir, M. (2010). Environmental Kuznets Curve and the Role of Energy Consumption in Pakistan. Development Research Papers, 10(5). Retrieved from https://mpra.ub.unimuenchen.de/34929/

Stern, D. I. (2004). The Rise and Fall of the Environmental Kuznets Curve. World Development, 32(8), $1419-1439$. doi:10.1016/j.worlddev.2004.03.004

Van Alstine J., \& Neumayer, E. (2010). The environmental Kuznets curve. In: Gallagher K. P. (ed.). Handbook on trade and the environment, p. 49-59. doi: http://dx.doi.org/10.4337/9781848446045

WB. (2016). World Development Indicators of the World Bank. Retrieved November 14, 2016, from http://data.worldbank.org

Yandle, B., Vijayaraghavan, M., \& Bhattarai, M. (2002). The Environmental Kuznets Curve: A Primer. PERC Research Study 02-1. Retrieved November 10, 2017 from https://www.perc.org/articles/environmental-kuznets-curve 